\title{
Potential faster Arctic sea ice retreat triggered by snowflakes' greenhouse effect
}

\author{
Jui-Lin Frank Li ${ }^{1}$, Mark Richardson ${ }^{1,2}$, Wei-Liang Lee ${ }^{4}$, Eric Fetzer ${ }^{1}$, Graeme Stephens ${ }^{1}$, Jonathan Jiang ${ }^{1}$, \\ Yulan Hong ${ }^{3}$, Yi-Hui Wang ${ }^{6}$, Jia-Yuh Yu ${ }^{7}$, and Yinghui Liu $^{5}$ \\ ${ }^{1}$ Jet Propulsion Laboratory, California Institute of Technology, Pasadena, CA 91125, USA \\ ${ }^{2}$ Joint Institute for Regional Earth System Science and Engineering, University of California, Los Angeles, \\ CA 90095-7228, USA \\ ${ }^{3}$ Department of Earth, Ocean and Atmospheric Science, Florida State University, Tallahassee, FL 32304, USA \\ ${ }^{4}$ Research Center for Environmental Changes, Academia Sinica, Taipei, Taiwan \\ ${ }^{5}$ Cooperative Institute for Meteorological Satellite Studies, University of Wisconsin, Madison, WI 53706, USA \\ ${ }^{6}$ Center for Coastal Marine Sciences, California Polytechnic State University, San Luis Obispo, CA 93407, USA \\ ${ }^{7}$ Department of Atmospheric Sciences, National Central University, Taoyuan City, 32001, Taiwan
}

Correspondence: Jui-Lin Frank Li (juilin.f.li@jpl.nasa.gov)

Received: 8 September 2018 - Discussion started: 21 September 2018

Revised: 1 February 2019 - Accepted: 22 February 2019 - Published: 22 March 2019

\begin{abstract}
Recent Arctic sea ice retreat has been quicker than in most general circulation model (GCM) simulations. Internal variability may have amplified the observed retreat in recent years, but reliable attribution and projection requires accurate representation of relevant physics. Most current GCMs do not fully represent falling ice radiative effects (FIREs), and here we show that the small set of Coupled Model Intercomparison Project Phase 5 (CMIP5) models that include FIREs tend to show faster observed retreat. We investigate this using controlled simulations with the CESM1CAM5 model. Under 1pctCO2 simulations, including FIREs results in the first occurrence of an "ice-free" Arctic (monthly mean extent $<1 \times 10^{6} \mathrm{~km}^{2}$ ) at $550 \mathrm{ppm} \mathrm{CO}_{2}$, compared with $680 \mathrm{ppm}$ otherwise. Over $60-90^{\circ} \mathrm{N}$ oceans, snowflakes reduce downward surface shortwave radiation and increase downward surface longwave radiation, improving agreement with the satellite-based CERES EBAF-Surface dataset. We propose that snowflakes' equivalent greenhouse effect reduces the mean sea ice thickness, resulting in a thinner pack whose retreat is more easily triggered by global warming. This is supported by the CESM1-CAM5 surface fluxes and a reduced initial thickness in perennial sea ice regions by approximately $0.3 \mathrm{~m}$ when FIREs are included. This explanation does not apply across the CMIP5 ensemble in which inter-model variation in the simulation of other processes
\end{abstract}

likely dominates. Regardless, we show that FIRE can substantially change Arctic sea ice projections and propose that better including falling ice radiative effects in models is a high priority.

\section{Introduction}

The Arctic region is undergoing pronounced change, becoming warmer and wetter (Boisvert and Stroeve, 2015) while its land ice melts (Jacob et al., 2012; Kjeldsen et al., 2015) and spring arrives weeks earlier than in the 1990s (Post et al., 2018). Communities in the region may have to adapt to changing hunting seasons (Rolph et al., 2018), loss of coast that was previously protected by sea ice (Overeem et al., 2011) and surface destabilisation due to permafrost melt (Shiklomanov et al., 2017).

In particular, Arctic sea ice retreat potentially opens area for resource extraction or transport routes (Smith and Stephenson, 2013) and has national security implications for neighbouring states. Physically, sea ice affects both top-ofatmosphere and surface heat fluxes. In winter it insulates the ocean, restricting the leakage of heat to space via infrared cooling, and in summer it predominantly reflects sunlight and cools the surface (Tietsche et al., 2011). Throughout the year 
it restricts evaporation and therefore affects the hydrological cycle (Bintanja and Selten, 2014). It has been proposed that reduced sea ice extent may further smooth the latitudinal temperature gradient, thus weakening the high-latitude jets and making it easier to shift into a "wavy" pattern, which is associated with long-lived extreme events at mid-latitudes (Francis and Vavrus, 2012). However, these proposed impacts at lower latitudes are currently speculative and disputed (Cohen et al., 2014).

The recent rapid Arctic sea ice retreat included extreme minima in 2007 and 2012, which in particular received attention. Regarding the 2007 minimum, a reduction in cloudiness during the melt season relative to previous years was shown to change surface energy balance by enough to thin sea ice by up to $0.3 \mathrm{~m}$ over 3 months (Kay et al., 2008). Atmosphere and ocean dynamics may also export ice to lower latitudes. For example, stronger circulation associated with the Arctic Oscillation can increase the total area of new, thin ice but transport the thicker ice away from the coldest regions and leave it vulnerable to summer melting (Rigor et al., 2002). Surface pressure observations have been used to infer contributions to summer sea ice reduction due to anomalously high ice export through the Pacific sector in 2007 (Zhang et al., 2008) and the Fram Strait in 2012 (Smedsrud et al., 2017).

Based on CMIP5 output (Climate Model Intercomparison Project Phase 5; Taylor et al., 2012), the observed extreme low events and general retreating trend have been attributed to a combination of melt driven by global warming along with internal variability, such as extreme cloud anomalies affecting surface radiation (Kay et al., 2011), and from 1990 through the early 2000s potentially wind-driven factors (Rigor and Wallace, 2004). One recent study suggested an equally important role for anthropogenic warming and natural variability for the extreme 2012 loss (Kirchmeier-Young et al., 2017).

Reliable attribution requires the ability to quantify physical processes and relevant responses to each forcing. A better understanding of the processes that are responsible for sea ice retreat will help to reduce uncertainties in future projections. Accurate future projections are necessary for informed decisions with the changing Arctic, such as by investors or insurance companies who may wish to assess the risk associated with proposals for future shipping routes. A common criterion is determining if and when a seasonally "ice-free" Arctic will occur, arbitrarily defined as when sea ice extent falls below $1 \times 10^{6} \mathrm{~km}^{2}$. At this point the remaining ice would cluster around islands and coasts, leaving the basin largely open.

Climate models are crucial tools to inform projections but their Arctic response varies widely (Massonnet et al., 2012; Stroeve et al., 2012). The time at which the Arctic is likely to become ice-free under high radiative forcing in CMIP5, for example, ranged from 2041 to 2060 in Massonnet et al. (2012) while Stroeve et al. (2012) only stated that "a seasonally ice-free Arctic Ocean within the next few decades is a distinct possibility".
Observed summer retreat has been faster than the average CMIP5 model simulation and if the CMIP5 models do not adequately include factors that influence sea ice retreat then their projections will be biased. We have previously shown that the majority of CMIP5 models do not properly account for atmospheric ice in their radiation codes. While they include suspended ice, falling ice is excluded and this causes region-dependent biases in the surface energy budget that, for example, tend to result in a larger mean Antarctic sea ice extent (Li et al., 2017).

Here we focus on sea ice extent changes and the surface energy budget over oceans from 60 to $90^{\circ} \mathrm{N}$. In the simplest terms, falling ice should produce a year-round increase in downward surface longwave radiation $\left(\mathrm{LW}_{\downarrow}\right)$ and a decrease in downward surface shortwave radiation $\left(\mathrm{SW}_{\downarrow}\right)$, which will be greatest in local summer. Li et al. (2017) showed that in the Antarctic this results in a dampened annual cycle, with the increased wintertime $\mathrm{LW}_{\downarrow}$ restricting maximum sea ice extent, which then results in a lower albedo when the sun rises again. This lower albedo somewhat counteracts the reduction in sunlight arriving at the surface due to reflection by snowflakes.

With regards to the Arctic, we expect a somewhat different response due to (1) wintertime maximum extent being restricted by continental boundaries and boundaries with warm ocean currents, (2) generally thicker sea ice (Kurtz and Markus, 2012; Kwok and Cunningham, 2008) and (3) faster local warming under the early part of $\mathrm{CO}_{2}$-driven heating.

It is therefore possible that increased $\mathrm{LW}_{\downarrow}$ from falling ice radiative effects (FIREs) may not have a substantial effect on winter sea ice extent but may restrict its thickness. This should favour faster retreat in sea ice cover during both a typical summer melt season and long-term warming. However, if the maximum wintertime extent is not strongly affected then the albedo will begin the melt season at a similar level regardless of FIREs, and a non-FIRE simulation should have a stronger local sea ice albedo feedback due to its stronger $\mathrm{SW}_{\downarrow}$. The $\mathrm{SW}_{\downarrow}$ and $\mathrm{LW}_{\downarrow}$ effects from including FIREs should oppose each other and it is not necessarily obvious whether one factor will dominate.

From the Antarctic sea ice results of Li et al. (2017), we suspect that the longwave effect is more important for the mean state. Our hypothesis is that FIRE increases year-round $\mathrm{LW}_{\downarrow}$ and results in a thinner sea ice cover on average. It is then easier to melt this pack as temperatures warm and our hypothesis is related to the recent findings of Massonnet et al. (2018), who also describe several relevant physical processes. They found that across CMIP5 models, sea ice retreat is correlated with parameters representing seasonal growth and retreat. They considered differences between the level of sophistication of the sea ice components of the CMIP5 models and found that the background thickness was more strongly related to sea ice retreat than model sophistication. This sensitivity of sea ice retreat to initial thickness supports our hypothesis, although we focus on an atmo- 
spheric driver of changes in the initial mean state of thickness, namely FIREs.

As well as changes in the mean state which could affect retreat through the initial pack's robustness, it is also possible that local fluxes could vary in different ways under warming. For example, in a simulation in which FIREs are included, warming could raise the atmospheric melting layer during summer, leading to a reduction in snow water path in favour of rainfall, which is not included in the radiation code. The direct consequence of this would be to reduce the trend in $\mathrm{LW}_{\downarrow}$ and increase the trend in $\mathrm{SW}_{\downarrow}$, relative to a simulation in which FIREs are excluded. This ignores further coupling to atmospheric conditions that could similarly affect feedbacks.

Here we investigate the importance of FIRE using both standard CMIP5 output along with simulations with a CMIP5-era climate model, the National Center for Atmospheric Research, Department of Energy (NCAR-DOE) Coupled Earth System Model version 1 with the Coupled Atmosphere Model version 5 (CESM1-CAM5). We refer to these as our "controlled" simulations to emphasise that we controlled the inclusion of FIRE and to distinguish them from other studies' CESM1 simulations.

Our two main aims are to determine whether FIREs substantially change simulated Arctic sea ice and, more specifically, to test our hypothesis that FIRE tends to reduce mean initial sea ice thickness and thereby leave it more vulnerable to retreat under warming.

CMIP5 output will be used to determine whether differences in simulated sea ice can be detected between FIRE and non-FIRE models across the ensemble and if so whether the changes can be linked to radiative heat fluxes in a way consistent with our expectations from FIRE.

The CMIP5 models have many differences that may affect sea ice extent, most obviously in their sea ice components. The sea ice albedo schemes for example vary in their sophistication and treatment of snow on ice, melt bonds and response to temperature. The resultant inter-model spread in local albedo feedback does not appear to explain much of the inter-model variance in long-term retreat (Koenigk et al., 2014), but modelled sea ice albedo does correlate with the amplitude of the annual cycle sea extent (Karlsson and Svensson, 2013). As described in Massonnet et al. (2018), any process that affects the baseline thickness may be related to future retreat, and this includes ocean eddy heat flux (Horvat and Tziperman, 2018) and cloud schemes that affect surface radiation and temperature change. For example in CESM1-CAM5.1, matching the observed prevalence of mixed-phase clouds at low temperatures (Cesana et al., $2012,2015)$ results in approximately $1{ }^{\circ} \mathrm{C}$ more warming under $\mathrm{CO}_{2}$ doubling (Tan et al., 2016). Such a large increase in warming would be expected to also change projected sea ice extent. Differences in sea ice, ocean and atmosphere schemes may drive changes that confound detection of FIRE-driven sea ice effects across the CMIP5 ensemble; thus our analysis of controlled CESM1-CAM5 simulations in which the only difference is the inclusion of FIREs allows a direct comparison. In these simulations our analysis ignores coupled dynamical responses in favour of studying the surface radiative flux terms that provide a direct test of our hypothesis. The paper is structured as follows: Sect. 2 lists the data and methodology, Sect. 3 reports on the simulated and observed sea ice changes, Sect. 4 looks at the simulated and observed surface radiative fluxes, Sect. 5 synthesises and discusses the results and their limitations, and Sect. 6 concludes the paper.

\section{Methods and data}

\subsection{CMIP5 and CESM1-CAM5 simulations}

We use outputs from the CMIP5 archive (Taylor et al., 2012) and select models that provide all surface energy balance terms plus the fields necessary to calculate sea ice extent for the preindustrial control (piControl), historical and Representative Concentration Pathway 8.5 (RCP8.5; Riahi et al., 2011) scenarios. The historical scenarios run through 2005 , after which we append the RCP8.5 output. This is a scenario of very high radiative forcing, which we select to better identify forced response over internal variability, and we make no judgment about the probability that this forcing will occur. For each model we select the first simulation in each case, r1i1p1 in CMIP5 nomenclature, which results in 25 simulations.

We split these into two sub-ensembles depending on whether FIREs are allowed: those including snow radiative effects (CMIP5-SoN, $N=7$ ) and those in which falling snow radiative effects are not considered (CMIP5-NoS, $N=18$ ). All models are listed in Table 1 in the Supplement.

For CESM1-CAM5 we use previously published historical simulations ( $\mathrm{Li}$ et al., 2014), which are run on a spatial resolution close to a $1^{\circ} \times 1^{\circ}$ latitude-longitude grid and follow the CMIP5 historical protocol. CAM5 is one of the few atmospheric models that allows snow radiative interactions, and it does this thanks to a two-moment treatment of rain and snow. Falling snow mass and the crystal number concentration is diagnosed at each model level and time step and is related to an effective radius as detailed in Sect. 2 of Morrison and Gettelman (2008). The profile of snow mass and effective radius is then related to radiative properties using precomputed lookup tables based on an assumed ice habit mixture as described in Sect. 2.5 of Gettelman et al. (2010). The scheme only represents the stratiform component of falling ice and not that in convective towers, but the majority of Arctic snowfall will be included. With this scheme snow radiative effects can be allowed (CESM1-SoN) or disallowed (CESM1-NoS), and the inclusion or exclusion of FIREs is the only difference between the SoN and NoS simulations. The radiative effects of rain are not included in any of the CESM1-CAM5 simulations, but this is unlikely to be 
an issue for much of the Arctic. Even ignoring the differences in how rain and snow affect radiation, CloudSat radarbased products report that Arctic precipitation frequency and amount are dominated by snow (Behrangi et al., 2016).

The strength of FIREs and the simulated response of other properties to FIREs depend on the frequency as well as the intensity of snowfall. This is accounted for in the model as radiative transfer is calculated at each model time step even though outputs are only provided monthly. Note that the CESM1-SoN and CESM1-NoS simulations are independent and so will have different amounts and patterns of snowfall and that by including FIREs there can be coupled changes in heating rates, circulation and precipitation (Chen et al., 2018). We later use the SoN-NoS surface radiative flux differences because these include the fully coupled changes due to FIREs and are the properties most directly relevant for sea ice changes.

Unfortunately, output is not available for any RCP, which forces observational comparisons to end in 2005. To estimate how sea ice extent changes under greater forcing, we use output from available simulations following the CMIP5 1 pctCO2 protocol in which atmospheric $\mathrm{CO}_{2}$ increases at $1 \% \mathrm{yr}^{-1}$ for 140 years from an initial value near $280 \mathrm{ppm}$. Radiative forcing estimates differ, but typical values for quadrupled $\mathrm{CO}_{2}$ are $5.3-8.6 \mathrm{~W} \mathrm{~m}^{-2}$ (Forster et al., 2013), meaning that total forcing is similar to the historical-RCP8.5 series used for CMIP5. We use output from fully coupled CESM1-SoN and for CESM1-NoS runs following the historical and $1 \mathrm{pctCO} 2$ simulations.

\subsection{Sea ice extent}

Sea ice extent (SIE) is defined as the area of ocean with sea ice concentration (sic) greater than $15 \%$. This was originally developed for satellite-based passive microwave products to be a robust identifier of ice edges when compared against aircraft observations (Cavalieri et al., 1991). This threshold means retrieved sea ice edges are less sensitive to changing weather conditions or melt ponds on the ice, which may interfere with the observed brightness temperatures. For observations we use the National Snow and Ice Data Center (NSIDC) monthly series of total sea ice extent (Fetterer et al., 2017), which is calculated from gridded data on a nominal $25 \mathrm{~km}$ grid. We use the complete years that were available as analysis time: 1979-2017.

The standard CMIP5 output is the sea ice concentration within an ocean grid cell, and we calculate sea ice extent following a previously published method (Kirchmeier-Young et al., 2017) by reporting the total area of all of the model's native ocean grid cells with sic $>15 \%$ (see Fig S1 for verification of this calculation). This is not a fully consistent comparison due to differences in grid cell sizes and as observations may underestimate sea ice concentration in the presence of substantial melt ponds. Here we assume that these factors have little effect on the large-scale changes under study.
To represent the magnitude of changes in SIE, we apply optimised least squares (OLSs) to each calendar month's time series separately (e.g. all Januaries for 1979-2005) assuming Gaussian white noise and report both trend estimates and their associated errors. We justify this based on analysis of the detrended residuals of the NSIDC dataset applied to 1979-2005 and 1979-2017. While some months reject white noise at $p<0.05$ according to the Ljung-Box test applied for lag-1 autocorrelation, these results are not robust since no calendar month rejects white noise over both periods. No month shows residuals that are significantly different from normality according to the Kolmogorov-Smirnov test: see Table S2 for summary of Pearson's $r$, Ljung-Box $p$ and Kolmogorov-Smirnov $p$.

\subsection{Sea ice thickness}

Given that our hypothesis is that FIRE drives changes in the initial mean sea ice thickness, we also compare the CESM1SoN and CESM1-NoS sea ice thickness in the 1pctCO2 simulations. Regional average sea ice thickness is calculated by appropriately area-weighting the ice-covered area of each grid cell included in the region. For a consistent comparison we select all grid cells in which both simulations have greater than $80 \%$ mean sea ice concentration for all calendar months averaged over years 1-20 and 21-40 of their 1 pctCO2 simulations. The selected region changes between each period, and a static region poleward of $80^{\circ} \mathrm{N}$ as in Massonnet et al. (2018) is also shown. The $80 \%$ concentration threshold means the areas are consistently ice covered and includes about 5 times as much area as using a $90 \%$ threshold. Thus, our thicknesses are more representative than using a stricter cut-off (Fig. S2). The mean thickness in each region is calculated for each calendar month and our hypothesis is supported if the CESM1-SoN mean thickness is greater than the CESM1-NoS mean thickness in this region.

\subsection{Surface energy budget}

We use $1^{\circ} \times 1^{\circ}$ monthly estimates of surface fluxes from the Clouds and the Earth's Radiant Energy System Energy Balanced and Filled-Surface (CERES EBAF-Surface; Kato et al., 2013) product, for which we have complete years for 2001-2015. CERES EBAF-Surface combines satellite data with a radiative transfer model to calculate surface fluxes and is estimated to have a monthly root-mean-square error of $\pm 11 \mathrm{~W} \mathrm{~m}^{-2}$ in each surface radiative flux term over oceans (Kato et al., 2012).

CESM1-CAM5 output is provided monthly at $1^{\circ} \times 1^{\circ}$, and for all CMIP5 models we use previously interpolated $2.5^{\circ} \times 2.5^{\circ}$ monthly data. Fluxes are calculated by taking the area-weighted average of values in each grid cell after scaling by the ocean fraction (total ocean fraction, including sea-ice-covered ocean). For CERES and CESM1CAM5 we use the CESM1-CAM5 land sea mask, and for 
all CMIP5 models we use a consistent fractional land sea mask built from the $0.125^{\circ} \times 0.125^{\circ}$ European Center for Medium Range Weather Forecasts European ReanalysisInterim (ECMWF ERA-Interim) land mask. For comparison of the mean state fluxes between CERES and our controlled historical CESM1-CAM5 simulations, we only have 5 complete years of overlap, 2001-2005 inclusive.

We consider the difference of CESM1-CAM5 minus CERES but since our simulations are coupled, internal variability could increase the apparent model-observation discrepancy. As an estimate of the magnitude of internal variability on our 5-year averaged fluxes, we detrend the model output over 1981-2005 and the CERES output over 20012015 and then slice these into non-overlapping 5-year periods. The standard deviation is calculated for the modelled and observation-based samples, and then these are added in quadrature to provide a value for the CESM1-CAM5 minus CERES difference. This estimate only represents the effect of internal variability due to our use of a short time period and may be biased if the variance in these terms changed greatly from 1979 to 2015 . Given the brevity of the available data record, we consider this simple approach to be adequate.

\section{Observed and simulated sea ice extent and thickness results}

\subsection{Sea ice extent}

Figure 1 shows the March and September post-1979 SIE in NSIDC observations and CMIP5 simulations. These are the months of maximum and minimum SIE (all months are shown in Fig. S3). Figure 1b shows that observed September retreat approaches the lower 10th percentile of the CMIP5 ensemble. When plotted using anomalies, the retreat falls outside the model range (see Fig. S4 for absolute anomalies, Fig. S5 for relative anomalies).

In Fig. 1c, d the results are split into CMIP5-SoN and CMIP5-NoS sub-ensembles, with Fig. 1d showing that CMIP5-SoN better captures the observed September retreat over 1979-2017. The median CMIP5-SoN trend is more negative than that of CMIP5-NoS from June through October, in better agreement with observations (Fig. S6). In March, trends are similar but CMIP5-SoN shows a greater extent, which is the opposite of expectations if wintertime $\mathrm{LW}_{\downarrow}$ from FIREs was the main cause of differences. However, intermodel differences in parameterisations and calculation methods for the atmosphere, oceans and sea ice can change the mean state; thus to isolate FIREs we present the controlled CESM1-CAM5 simulations in Fig. 2.

Over 1979-2005 there is a smaller discrepancy between CESM1-CAM5 and observations for monthly mean extent when including FIRE (see Fig. S7). Retreat during the same period is faster in CESM1-SoN than in CESM1-NoS: for September the SoN-minus-NoS series is significant at
$2.61 \sigma$ (white noise $p=0.01$, see Fig. S8). The CESM1-SoN September retreat is faster than in reality over 1979-2005 but not significantly so $(p=0.06)$. Real world Arctic sea ice retreated more rapidly after 2005 , but we do not have the output to determine whether this means that CESM1-SoN would then show better agreement. For increased warming we must turn to the 1 pctCO2 output, and Fig. $2 \mathrm{~d}$ shows accelerated retreat in CESM1-SoN following year 40, corresponding to $\mathrm{CO}_{2}$ levels of $416 \mathrm{ppm}$, a value that current trends suggest will occur in the 2020s.

To allow easier interpretation, we take overlapping decadal averages of mean SIE and the number of years within that decade with SIE $<1 \times 10^{6} \mathrm{~km}^{2}$ and plot these as a function of atmospheric $\mathrm{CO}_{2}$ concentration (year 0 is approximately 280 ppm) in Fig. 3. Below the 2017 atmospheric $\mathrm{CO}_{2}$ concentration, Fig. 3a shows only small differences in decadal mean September SIE, but for concentrations higher than this the Arctic sea ice retreats far more rapidly under global warming when FIREs are included. Note that these simulations exclude non- $\mathrm{CO}_{2}$ forcings such as aerosol, which are present in reality. In the CESM1-SoN simulation, Fig. 3b shows that the majority of years are classified as ice free once atmospheric $\mathrm{CO}_{2}$ passes $550 \mathrm{ppm}$, compared with $680 \mathrm{ppm}$ in the CESM1-NoS simulation. In a naïve sense (i.e. assuming an approximately constant airborne fraction as occurs for these decades in some $1 \mathrm{pctCO} 2$ simulations; e.g. Matthews et al., 2009) this implies a difference of almost $100 \%$ in cumulative future anthropogenic $\mathrm{CO}_{2}$ emissions before the Arctic commonly becomes ice free if these CESM1-CAM5 $1 \mathrm{pctCO} 2$ simulations are representative of the real world. Figure 3 shows that the potential impact of FIREs on Arctic sea ice retreat is large, but we do not argue that this necessarily means that Arctic sea ice will collapse more rapidly than indicated by CMIP5. Firstly, CESM1-CAM5 may have compensating biases due to other processes and secondly the disappearance of ice under transient $\mathrm{CO}_{2}$-driven warming may not correspond to reality in which a mixture of radiative forcing agents is changing. Some of these, such as aerosols, may drive stronger seasonal, regional, and dynamic responses than well-mixed greenhouse gases like $\mathrm{CO}_{2}$ (Hansen et al., 1997).

A further consideration is that internal variability can change when an ice-free state occurs. Under RCP8.5 the CESM1 large ensemble of 40 runs (Kay et al., 2015) shows a 14-year range between members when ice free is defined based on the 5-year average (Jahn et al., 2016). The CESM1SoN to CESM1-NoS 1pctCO2 difference by this criterion is 20 years. Thus, our conclusion that FIRE drives faster retreat is likely robust to internal variability.

These simulations show that falling ice radiative effects could lead to much greater Arctic sea ice retreat when the system is forced under global warming and support the inclusion of FIRE in future modelling efforts. Next, we investigate whether the surface radiative energy balance allows us to identify candidate physical processes that explain these 

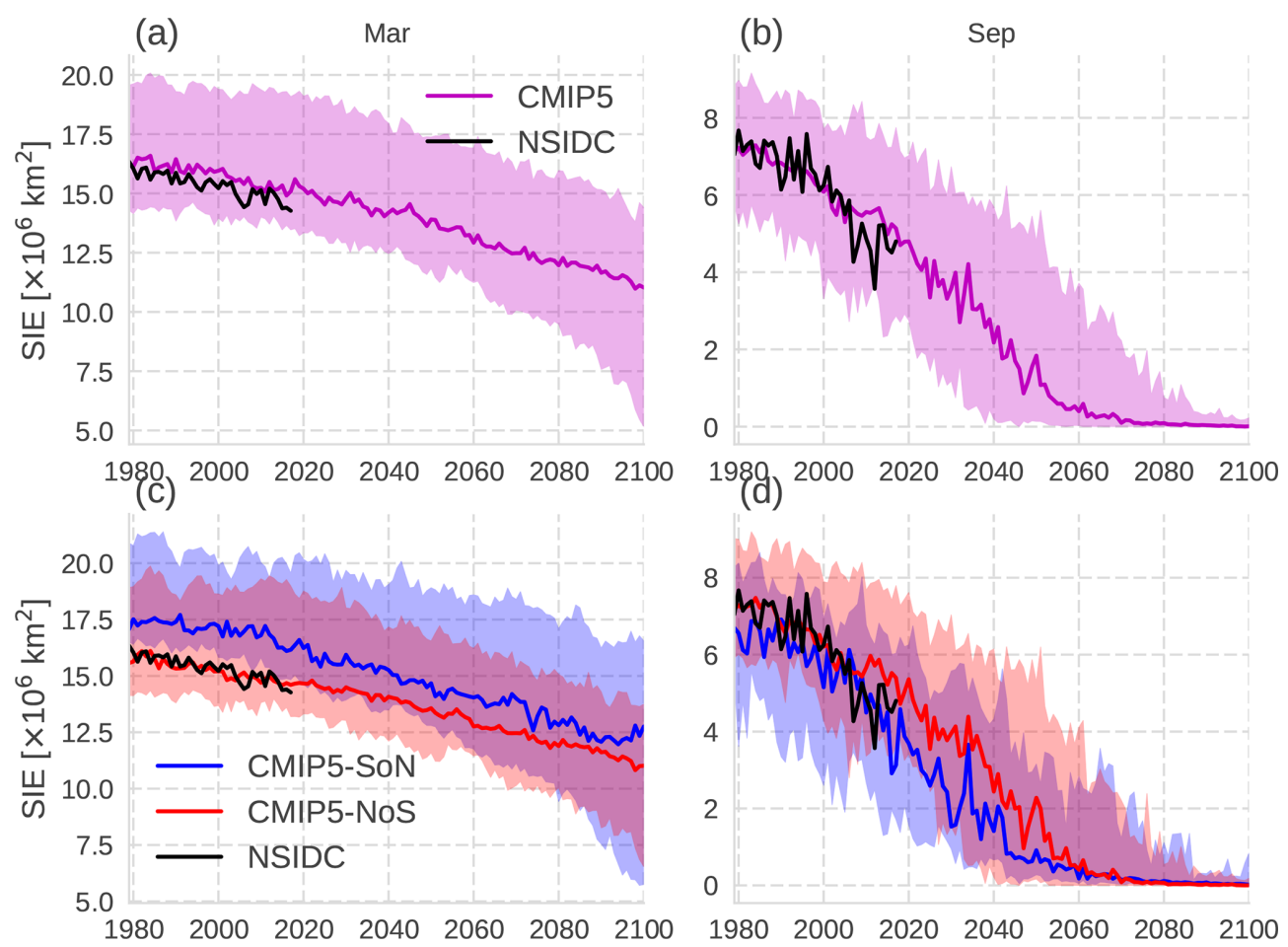

Figure 1. Arctic sea ice extent in NSIDC observations (black) and CMIP5 climate models (line is ensemble median, shading is $10 \%-90 \%$ range). (a) Full ensemble in March, (b) full ensemble in September, (c) CMIP5 split into sub-ensembles of models with FIRE (CMIP5-SoN) and those without (CMIP5-NoS) in March, and (d) SoN and NoS in September.
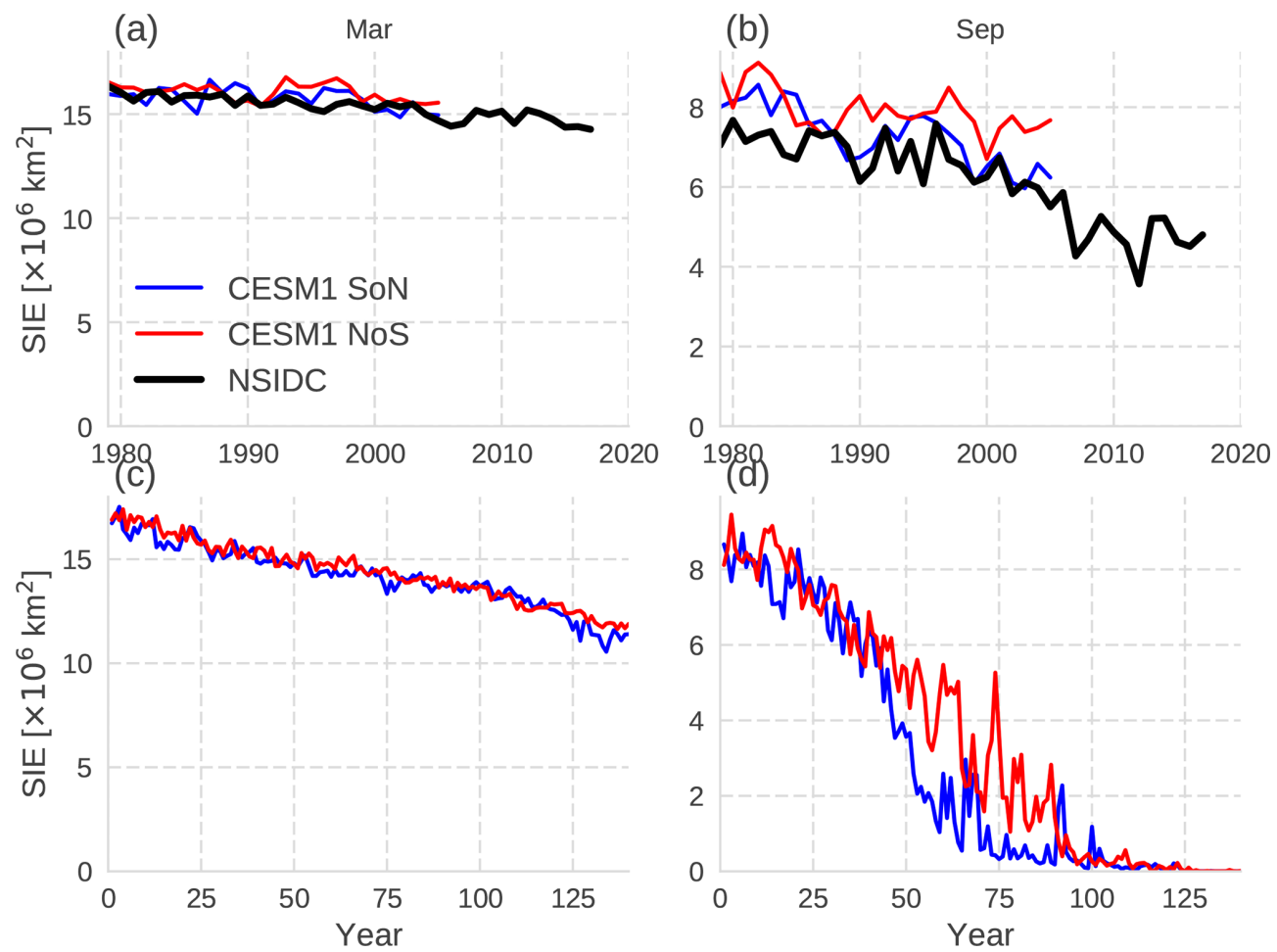

Figure 2. Observed (black) CESM1-CAM5-simulated Arctic sea ice extent in (a) March using the protocol CMIP5 historical simulation, (b) September in the historical simulation, (c) March in 1pctCO2 and (d) September in 1pctCO2. Blue lines are with snow radiative effects $(\mathrm{SoN})$ and red without $(\mathrm{NoS})$. 
(a)

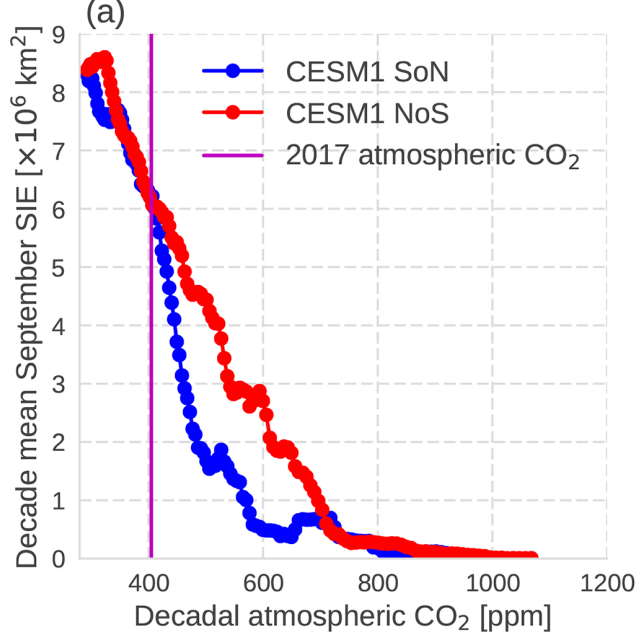

(b)

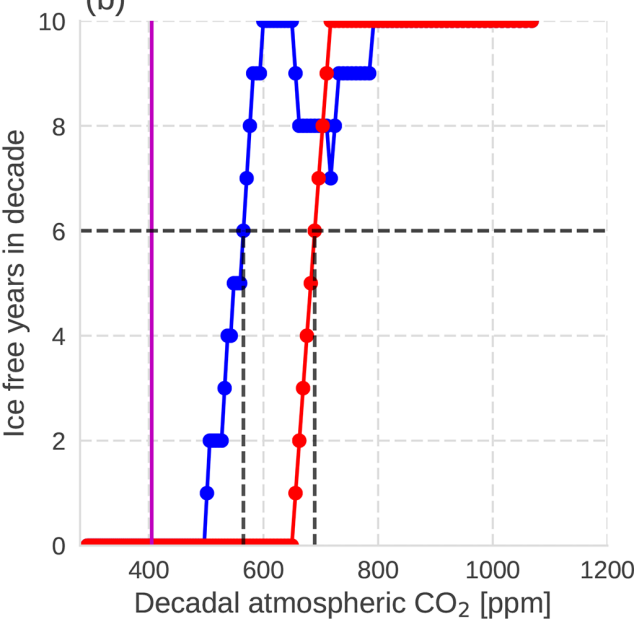

Figure 3. Changes in September Arctic sea ice under $1 \% \mathrm{yr}^{-1} \mathrm{CO}_{2}$ increases for CESM1 SoN (blue) and CESM1 NoS (red) as a function of decade-mean atmospheric $\mathrm{CO}_{2}$. (a) The decadal mean sea ice extent and (b) the number of years within that decade for which SIE $<$ $1 \times 10^{6} \mathrm{~km}^{2}$, commonly taken as representative of an ice-free Arctic Ocean basin. The atmospheric $\mathrm{CO}_{2}$ concentration in 2017 is shown as a vertical magenta line and the dashed lines in (b) identify the decade-mean atmospheric $\mathrm{CO}_{2}$ level at which the majority of simulated years have $\mathrm{SIE}<1 \times 10^{6} \mathrm{~km}^{2}$.

changes and whether the processes identified using CESM1CAM5 can be detected across the CMIP5 ensemble.

\subsection{Sea ice thickness in CESM1-SoN and CESM1-NoS}

Figure $4 \mathrm{a}$, d outline the regions within which thickness is calculated for years 1-20 and 21-40, and the annual cycles of mean thickness for each period and simulation are shown in Fig. 4b, c, e, f. Consistent with our hypothesis, the CESM1SoN ice pack starts off thinner than that of CECSM1-NoS. Over the Arctic interior the pack tends to be $20-30 \mathrm{~cm}$ thinner throughout the year. The remaining perennial $>80 \%$ sea ice concentration region for years $21-40$ in Fig. 4 e shows a $1.4 \mathrm{~m}$ difference.

\section{Observed and simulated surface radiative fluxes}

\subsection{CESM1-CAM5 controlled simulations}

In Sect. 1 we discussed the expected direct effects of FIREs on surface longwave (LW) and shortwave (SW) radiative fluxes and how these might be related to SIE. We begin our analysis with the downward fluxes at the surface, $\mathrm{LW}_{\downarrow}$ and $\mathrm{SW}_{\downarrow}$ in CESM1-CAM5 compared with CERES EBAFSurface observations during their overlap period of 20012005. Uncertainties are based on the standard deviation of non-overlapping 5-year periods from the rest of their records as described in Sect. 2. The CESM1-CAM5 minus CERES EBAF-Surface flux differences over $60-90^{\circ} \mathrm{N}$ oceans are displayed in Fig. 5 for each calendar month. As expected, inclusion of FIREs results in increased $\mathrm{LW}_{\downarrow}$ and decreased $\mathrm{SW}_{\downarrow}$, resulting in better agreement with the observation- based CERES data. Figure 5a shows that the $\mathrm{LW}_{\downarrow}$ difference is greatest in winter, when the $\mathrm{SW}_{\downarrow}$ is negligible due to the lack of available sunlight. The SoN-NoS difference in $\mathrm{SW}_{\downarrow}$ is greater than in $\mathrm{LW}_{\downarrow}$ during summer, but only marginally so, and the annual average $\mathrm{LW}_{\downarrow}$ difference is greater. From Fig. $5 \mathrm{~b}$, the net absorbed surface SW radiation shows relatively small SoN-NoS differences because while the FIRE reduces $\mathrm{SW}_{\downarrow}$, it also reduces SIE and so lowers the mean albedo. The net absorbed surface longwave radiation is consistently greater in SoN, explaining the majority of the remaining difference in net radiation in Fig. 5c. The annual average $\mathrm{LW}_{\downarrow}$ is $11 \mathrm{~W} \mathrm{~m}^{-2}$ higher when including FIREs, which will increase mean ice temperature and increase heat input, resulting in a thinner pack that is more vulnerable to warming.

It is also possible that local radiative feedbacks could be different when including or excluding FIRE. This would manifest as a change in the SoN-minus-NoS flux differences over time and for this we switch back to analysis of the 1 pctCO2 simulations. Figure 6 includes the 1 pctCO2 $\mathrm{SW}_{\downarrow}$ and $\mathrm{LW}_{\downarrow}$ differences for each season: December-JanuaryFebruary (DJF), March-April-May (MAM), June-JulyAugust (JJA) and September-October-November (SON). Long-term trends are estimated by multiplying the OLS trend gradient by the length of the period, and the only significant $(p<0.05)$ trend occurs in SON when there is a decrease in the radiative flux difference between the two simulations.

However, the SoN-minus-NoS $\mathrm{LW}_{\downarrow}$ trend is insignificantly positive during the first 70 years $(+0.08 \pm$ $0.09 \mathrm{~W} \mathrm{~m}^{-2} \mathrm{yr}^{-1}, \pm 2 \sigma$ error in OLS trend), so the fullperiod $\mathrm{LW}_{\downarrow}$ trend is not responsible for driving the faster disappearance of sea ice in CESM1-SoN that has largely oc- 


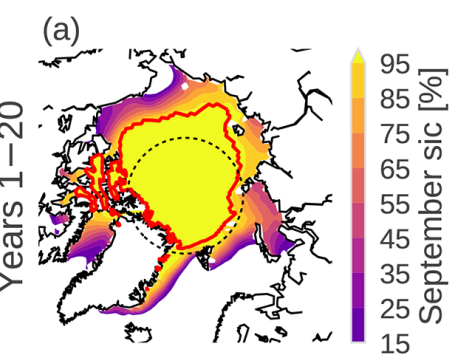

(d)

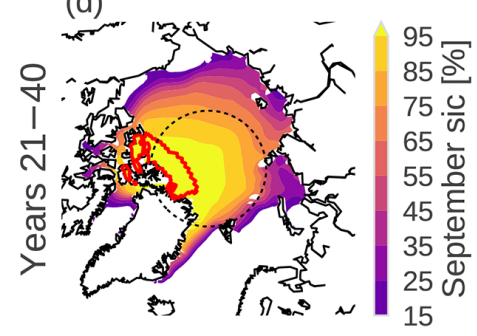

(b) Red contour region

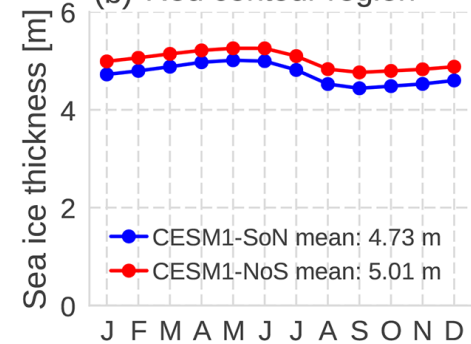

(e)

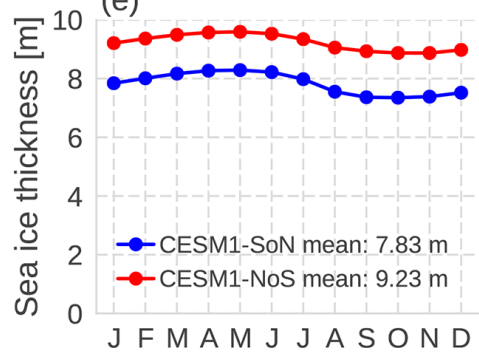

(c) $\quad 80-90^{\circ} \mathrm{N}$

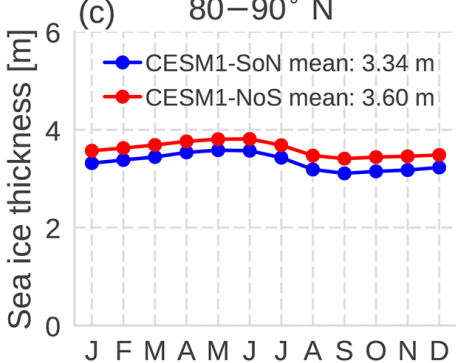

(f)

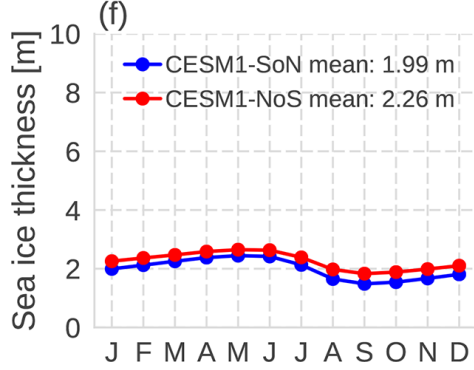

Figure 4. (a) CESM1-SoN September mean sea ice concentration over years 1-20 in 1pctCO2; the black dashed line is $80^{\circ} \mathrm{N}$ and the red contour encloses the region within which the mean sea ice concentration exceeds $80 \%$ in all calendar months for both CESM1-SoN and CESM1-NoS. (b) Mean thickness within the red contour for years 1-20; (c) mean thickness poleward of 80 $\mathrm{N}$ for years 1-20. Panels (d)-(f) are like (a)-(c) but for years 21-40.

(a)

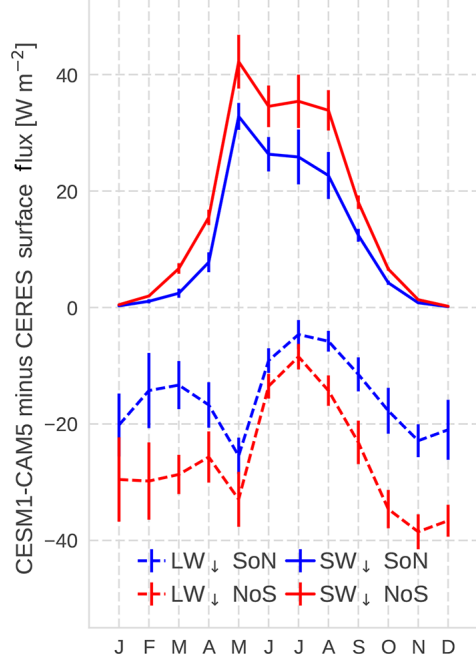

(b)

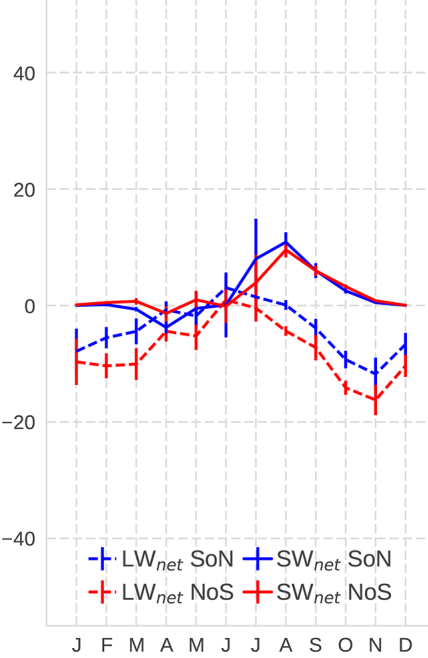

(c)

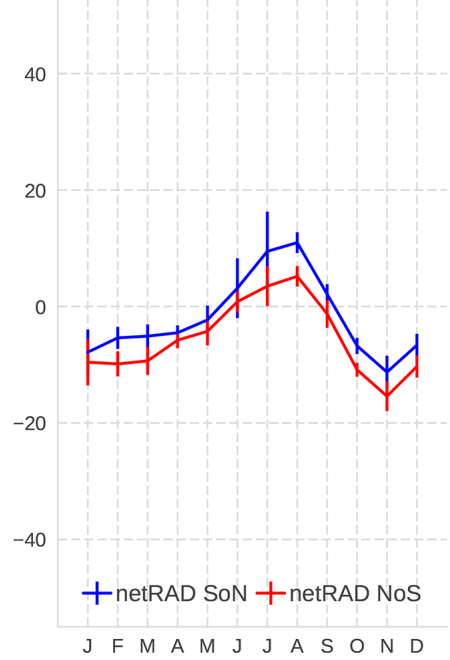

Figure 5. CESM1-minus-CERES $60-90^{\circ} \mathrm{N}$ ocean differences in mean surface fluxes for each calendar month over 2001-2005. Differences are shown for both CESM1-SoN (blue) and CESM1-NoS (red). Error bars are estimates of internal variability only, based on standard deviations of non-overlapping 5-year periods in each series after detrending the annual data. (a) Differences in downward longwave (dashed) and downward shortwave (solid) radiation. (b) Difference in net longwave (dashed, positive downward) and net shortwave (solid) radiation. (c) Net downward radiation sum. All values are defined such that positive indicates a case in which the model value shows greater net downward flux than the CERES value.

curred by year 70 (as shown by Fig. 2d for September). Instead, the difference appears related to differences in the relative effects of FIRE between icy and ice-free states. During the first 40 years when the simulations both have a healthy Arctic ice cover, the mean SON difference in $\mathrm{LW}_{\downarrow}$ is $11.6 \pm 11.1 \mathrm{~W} \mathrm{~m}^{-2}$ ( \pm 2 standard deviations), whereas for the final 40 years when both simulations are ice free during September, the difference is $7.1 \pm 6.6 \mathrm{~W} \mathrm{~m}^{-2}$. This difference could be related to changes in cloud properties or phase in response to sea ice cover; the CESM1-SoN simulation initially has a smaller sea ice extent but by the end of the simulation both CESM1-SoN and CESM1-NoS are largely ice free. 
(a)

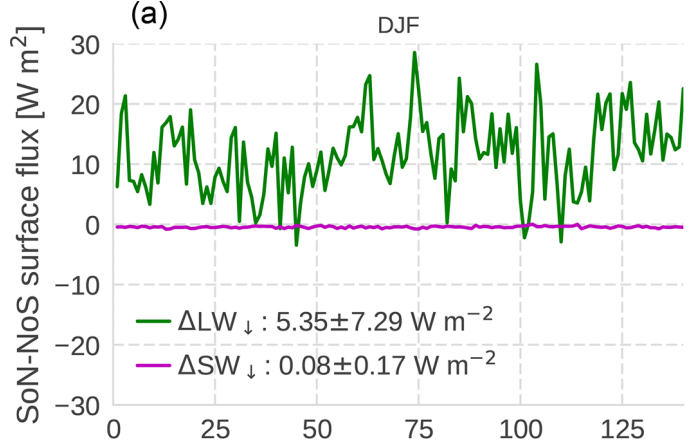

(c)

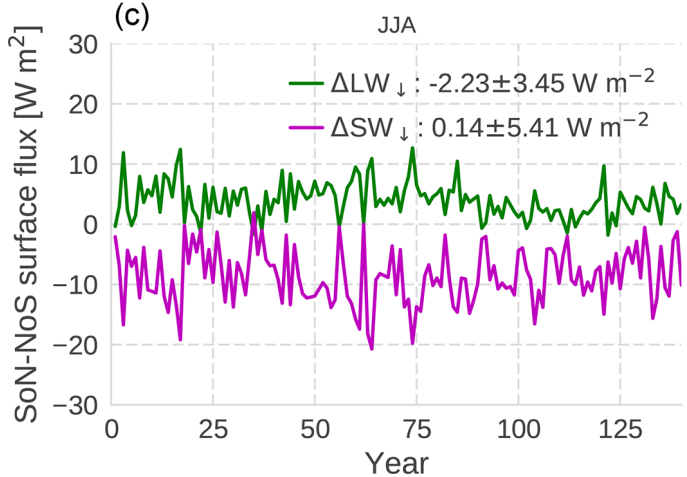

(b)

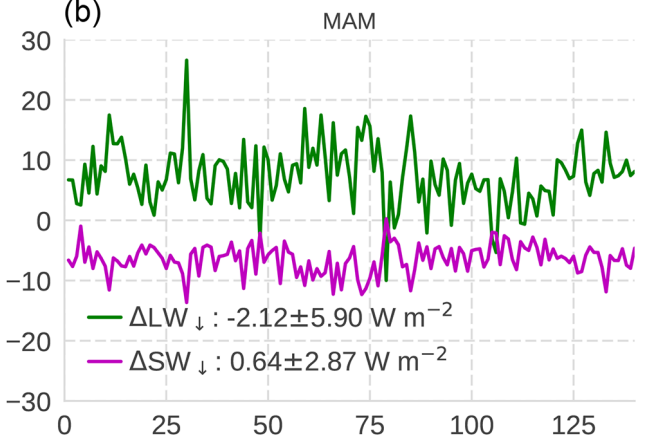

(d)

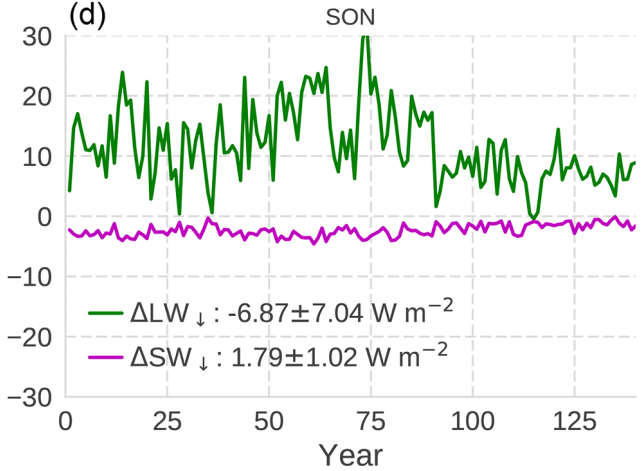

Figure 6. The 1pctCO2 CESM1-SoN-minus-CESM1-NoS season differences in downward surface fluxes over $60-90^{\circ} \mathrm{N}$ oceans. The legend reports the estimate of the 140-year change in this difference by multiplying the linear regression trend coefficient by 140 , with $\pm 2 \sigma$ uncertainties. (a) December-January-February, (b) March-April-May, (c) June-July-August and (d) September-October-November.

Taken together, the energy budget analysis of CESM1CAM5 1pctCO2 simulations indicates that differences in flux trends due to FIRE do not drive the faster observed retreat, but instead the effect of stronger year-round $\mathrm{LW}_{\downarrow}$ in the initial state is the most important radiative contribution. This supports our argument that the effective greenhouse effect from snowflakes results in a thinner pack whose retreat is more easily triggered by warming. This snowflake greenhouse effect is present year round and throughout the entire Arctic basin, leaving no safe spaces where the ice can fully recover.

\subsection{CMIP5 ensemble results}

The CESM1-CAM5 results show that snow radiative effects can substantially change simulated Arctic sea ice retreat under warming, which is consistent with the generally earlier disappearance of sea ice seen under historical-RCP8.5 simulations for the CMIP5-SoN sub-ensemble, compared with the CMIP5-NoS ensemble. To investigate this, we consider the CMIP5 1979-2005 mean annual cycle and the 2006-2035 linear regression trends for each calendar month for a variety of properties in Fig. 7. Each simulation's line is coloured according to whether it includes FIREs (SoN, blue) or excludes FIREs (NoS, red).

The mean state period is the overlap between NSIDC passive microwave sea ice extent data and the historical simula- tions, and the trend period covers 30 years in which Fig. 1 shows an apparent notable divergence in SIE between the CMIP5-SoN and CMIP5-NoS sub-ensembles.

Inspection of Fig. 7 shows no clear support across the CMIP5 ensemble for the hypothesis we developed using the controlled CESM1-CAM5 simulations. In fact, Fig. 7d shows that two models that include FIREs show substantially more summertime $\mathrm{SW}_{\downarrow}$ (e.g. $45 \mathrm{~W} \mathrm{~m}^{-2}$ more than the median of all other CMIP5 models), which is the opposite of the direct effects we hypothesise are related to FIREs. These models are GISS-E2-H and GISS-E2-R, whose CMIP5 versions greatly underestimated mean ice water path (IWP) poleward of $60-90^{\circ} \mathrm{N}$ (Stanfield et al., 2014). This illustrates how other differences aside from FIREs may well have compensating effects, showing that the FIRE alone is insufficient to explain differences in Arctic sea ice retreat among models.

\section{Discussion and conclusions}

The apparent agreement in September sea ice retreat between CMIP5-SoN and CESM1-SoN seen in Figs. 1 and 2 appears supportive of a major role for falling ice radiative effects in reinforcing Arctic sea ice retreat. However, the CMIP5 result was largely due to extremely early ice disappearance in the GISS-E2 models, which accounted for two out of seven of the sub-ensemble members. These models have been shown 
(a)

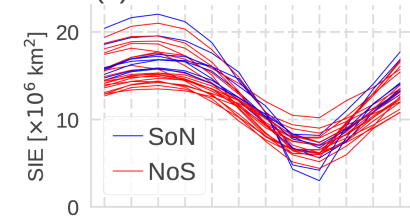

(c)

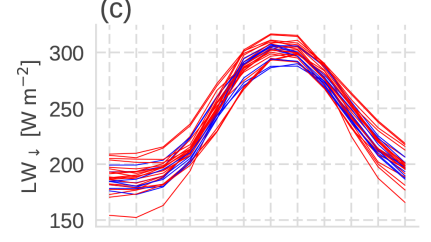

(e)

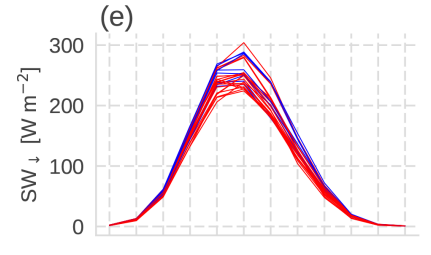

(g)

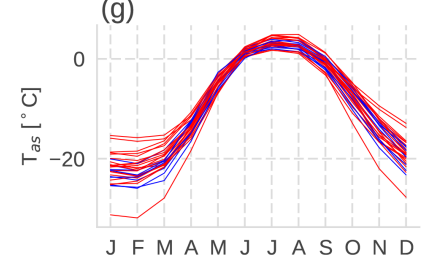

(b)

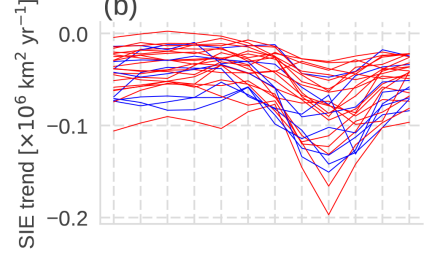

(d)
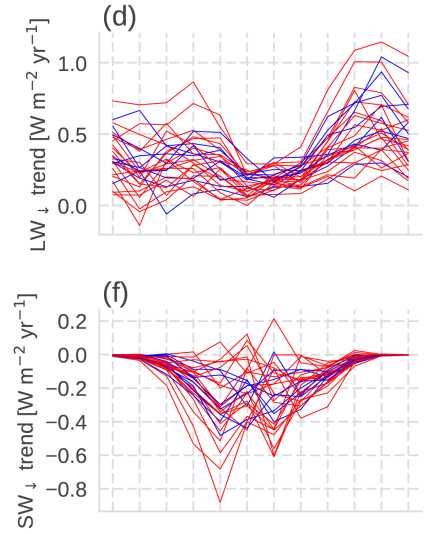

(h)

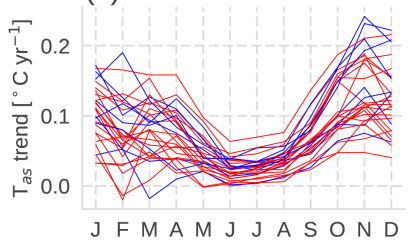

Figure 7. Output over $60-90^{\circ} \mathrm{N}$ oceans from individual CMIP5 historical-RCP8.5 simulations according to whether the simulation includes FIREs (blue) or excludes them (red). The left panels show annual cycles of mean properties from 1979 to 2005 and the right panels show the trend for each calendar month over 2006-2035. (a-b) Sea ice extent, (c-d) downward longwave radiation at the surface, (e-f) downward shortwave radiation at the surface and (g-h) near-surface air temperature.

to drastically underestimate total ice water path, resulting in too much $\mathrm{SW}_{\downarrow}$ during summer and therefore likely a very strong surface albedo feedback. As detailed in Sect. 1, simulated sea ice is affected by many model design factors including the sea ice albedo scheme, ocean eddy heat transport and cloud simulations. Therefore, the CMIP5 cross comparison simply shows that Arctic sea ice projections are at least as sensitive to other factors as to the inclusion or exclusion of FIREs, and the faster September retreat of CMIP5-SoN in Fig. 1 is likely due to the full combination of properties in these models and not directly due to FIREs. Nevertheless, the controlled CESM1-CAM5 simulations demonstrate that the inclusion of FIREs in this model results in a thinner sea ice pack and a faster retreat in extent over both 1979-2005 and in $1 \mathrm{pctCO} 2$ simulations. The difference between CESM1-SoN and CESM1-NoS in 1pctCO2 is larger than the range of values due to internal variability spanned by the CESM1 large

ensemble; thus we conclude that we have detected a FIREdriven difference in modelled Arctic sea ice retreat.

We did not explore any dynamic changes in response to the inclusion of FIREs. However, the magnitude of the radiative effects are a credible candidate for explaining major differences in sea ice extent, with $11 \mathrm{~W} \mathrm{~m}^{-2}$ of downward longwave radiation over a year being sufficient to melt $\sim 1 \mathrm{~m}$ of ice annually assuming that all of the heat goes into the ice (Kay et al., 2008). In reality this thinning is reduced by negative feedbacks, and Fig. 4b, c show that in CESM1-CAM5 the net result is a thinning of approximately $30 \mathrm{~cm}$ of the interior ice pack, consistent with our hypothesis that the FIRE thins the Arctic ice pack and preconditions it for more rapid melt. Nevertheless, changes in dynamics that affect patterns of cloudiness, ice transport or ocean heat transport could reinforce or counteract our proposed changes and we have not investigated these.

In conclusion, we do not argue that the exclusion of FIREs in current models necessarily means that Arctic sea ice will retreat faster than simulated by the average CMIP5 model. CESM1-CAM5 might show a stronger sea ice response to FIREs than other models or, following inclusion of FIREs, that modellers might tune other processes in a way which counteracts FIRE-driven sea ice changes. Or a model may have a stronger summertime albedo feedback than longwave radiation-driven thinning effect and show slower retreat once FIREs are included. However, our controlled experiments show a strong sensitivity of sea ice projections to FIREs in at least one model, with Fig. 2d showing September Arctic sea ice retreat being approximately twice as fast once atmospheric $\mathrm{CO}_{2}$ concentrations are above 2017 levels under $1 \% \mathrm{yr}^{-1} \mathrm{CO}_{2}$ growth. Given that the snow radiative effect exists in reality, we encourage other modelling groups to include them in future cloud schemes to increase confidence in Arctic sea ice projections.

Data availability. The NSIDC (ftp://sidads.colorado.edu/ DATASETS/NOAA/G02135/north/monthly/data/, last access: August 2018), CERES EBAF (https://ceres.larc.nasa. gov/order_data.php, last access: July 2018) and CMIP5 data (https://cmip.llnl.gov/cmip5/data_portal.html, last access: January 2018) are available from public archives. The time series of CMIP5 and CESM1 sea ice and radiative fluxes are appended as the Supplement.

Supplement. The supplement related to this article is available online at: https://doi.org/10.5194/tc-13-969-2019-supplement.

Author contributions. JLL led the research and performed the CESM1 sensitivity output processing and analysis. WLL conducted CESM1 model sensitivity runs. MR performed the CMIP5 processing and the time series analysis. YHW, YLH and JYY provided dis- 
cussion and editing. EF, JJ and GS supported and offered comments and suggestions on the study. YL controlled the data for quality.

Competing interests. The authors declare that they have no conflict of interest.

Acknowledgements. Mark Richardson thanks Megan KirchmeierYoung for providing her CMIP5 sea ice extent series to allow verification of his code.

Edited by: Dirk Notz

Reviewed by: Abhay Devasthale and Anina Gilgen

\section{References}

Behrangi, A., Christensen, M., Richardson, M., Lebsock, M., Stephens, G., Huffman, G. J., Bolvin, D., Adler, R. F., Gardner, A., Lambrigtsen, B., and Fetzer, E.: Status of high-latitude precipitation estimates from observations and reanalyses, J. Geophys. Res., 121, 4468-4486, https://doi.org/10.1002/2015JD024546, 2016.

Bintanja, R. and Selten, F. M.: Future increases in Arctic precipitation linked to local evaporation and sea-ice retreat, Nature, 509, 479-482, https://doi.org/10.1038/nature13259, 2014.

Boisvert, L. N. and Stroeve, J. C.: The Arctic is becoming warmer and wetter as revealed by the Atmospheric Infrared Sounder, Geophys. Res. Lett., 42, 4439-4446, https://doi.org/10.1002/2015GL063775, 2015.

Cavalieri, D. J., Crawford, J. P., Drinkwater, M. R., Eppler, D. T., Farmer, L. D., Jentz, R. R., and Wackerman, C. C.: Aircraft active and passive microwave validation of sea ice concentration from the Defense Meteorological Satellite Program special sensor microwave imager, J. Geophys. Res., 96, 21989, https://doi.org/10.1029/91JC02335, 1991.

Cesana, G., Kay, J. E., Chepfer, H., English, J. M., and de Boer, G.: Ubiquitous low-level liquid-containing Arctic clouds: New observations and climate model constraints from CALIPSO-GOCCP, Geophys. Res. Lett., 39, L20804, https://doi.org/10.1029/2012GL053385, 2012.

Cesana, G., Waliser, D. E., Jiang, X., and Li, J.-L. F.: Multimodel evaluation of cloud phase transition using satellite and reanalysis data, J. Geophys. Res.-Atmos., 120, 7871-7892, https://doi.org/10.1002/2014JD022932, 2015.

Chen, C.-A., Li, J.-L. F., Richardson, M., Lee, W.-L., Fetzer, E., Stephens, G., Hsu, H.-H., Wang, Y.-H., and Yu, J.-Y.: Falling Snow Radiative Effects Enhance the Global Warming Response of the Tropical Pacific Atmosphere, J. Geophys. Res.-Atmos., 123, 10109-10124, https://doi.org/10.1029/2018JD028655, 2018.

Cohen, J., Screen, J. A., Furtado, J. C., Barlow, M., Whittleston, D., Coumou, D., Francis, J., Dethloff, K., Entekhabi, D., Overland, J., and Jones, J.: Recent Arctic amplification and extreme mid-latitude weather, Nat. Geosci., 7, 627-637, https://doi.org/10.1038/ngeo2234, 2014.

Fetterer, F., Knowles, K., Meier, W., Savoie, M., and Windnagel, A. K.: updated daily. Sea Ice Index, Version 3 [NH Monthly Sea Ice
Extent], Boulder, Colorado, USA, NSIDC Natl., Snow Ice Data Center, https://doi.org/10.7265/N5K072F8, 2017.

Forster, P. M., Andrews, T., Good, P., Gregory, J. M., Jackson, L. S., and Zelinka, M.: Evaluating adjusted forcing and model spread for historical and future scenarios in the CMIP5 generation of climate models, J. Geophys. Res.-Atmos., 118, 11391150, https://doi.org/10.1002/jgrd.50174, 2013.

Francis, J. A. and Vavrus, S. J.: Evidence linking Arctic amplification to extreme weather in mid-latitudes, Geophys. Res. Lett., 38, L02707, https://doi.org/10.1029/2012GL051000, 2012.

Gettelman, A., Liu, X., Ghan, S. J., Morrison, H., Park, S., Conley, A. J., Klein, S. A., Boyle, J., Mitchell, D. L., and Li, J.-L. F.: Global simulations of ice nucleation and ice supersaturation with an improved cloud scheme in the Community Atmosphere Model, J. Geophys. Res., 115, D18216, https://doi.org/10.1029/2009JD013797, 2010.

Hansen, J., Sato, M., and Ruedy, R.: Radiative forcing and climate response, J. Geophys. Res.-Atmos., 102, 6831-6864, https://doi.org/10.1029/96JD03436, 1997.

Horvat, C. and Tziperman, E.: Understanding Melting due to Ocean Eddy Heat Fluxes at the Edge of Sea-Ice Floes, Geophys. Res. Lett., 45, 9721-9730, https://doi.org/10.1029/2018GL079363, 2018.

Jacob, T., Wahr, J., Pfeffer, W. T., and Swenson, S.: Recent contributions of glaciers and ice caps to sea level rise, Nature, 482 , 514-518, https://doi.org/10.1038/nature10847, 2012.

Jahn, A., Kay, J. E., Holland, M. M., and Hall, D. M.: How predictable is the timing of a summer icefree Arctic?, Geophys. Res. Lett., 43, 9113-9120, https://doi.org/10.1002/2016GL070067, 2016.

Karlsson, J. and Svensson, G.: Consequences of poor representation of Arctic sea-ice albedo and cloud-radiation interactions in the CMIP5 model ensemble, Geophys. Res. Lett., 40, 4374-4379, https://doi.org/10.1002/grl.50768, 2013.

Kato, S., Loeb, N. G., Rutan, D. A., Rose, F. G., Sun-Mack, S., Miller, W. F., and Chen, Y.: Uncertainty Estimate of Surface Irradiances Computed with MODIS-, CALIPSO-, and CloudSatDerived Cloud and Aerosol Properties, Surv. Geophys., 33, 395 412, https://doi.org/10.1007/s10712-012-9179-x, 2012.

Kato, S., Loeb, N. G., Rose, F. G., Doelling, D. R., Rutan, D. A., Caldwell, T. E., Yu, L., and Weller, R. A.: Surface Irradiances Consistent with CERES-Derived Top-of-Atmosphere Shortwave and Longwave Irradiances, J. Climate, 26, 27192740, https://doi.org/10.1175/JCLI-D-12-00436.1, 2013.

Kay, J. E., L'Ecuyer, T., Gettelman, A., Stephens, G., and O’Dell, C.: The contribution of cloud and radiation anomalies to the 2007 Arctic sea ice extent minimum, Geophys. Res. Lett., 35, L08503, https://doi.org/10.1029/2008GL033451, 2008.

Kay, J. E., Holland, M. M., and Jahn, A.: Inter-annual to multi-decadal Arctic sea ice extent trends in a warming world, Geophys. Res. Lett., 38, L15708, https://doi.org/10.1029/2011GL048008, 2011.

Kay, J. E., Deser, C., Phillips, A., Mai, A., Hannay, C., Strand, G., Arblaster, J. M., Bates, S. C., Danabasoglu, G., Edwards, J., Holland, M., Kushner, P., Lamarque, J.-F., Lawrence, D., Lindsay, K., Middleton, A., Munoz, E., Neale, R., Oleson, K., Polvani, L., and Vertenstein, M.: The Community Earth System Model (CESM) Large Ensemble Project: A Community Resource for Studying Climate Change in the Presence of Inter- 
nal Climate Variability, B. Am. Meteorol. Soc., 96, 1333-1349, https://doi.org/10.1175/BAMS-D-13-00255.1, 2015.

Kirchmeier-Young, M. C., Zwiers, F. W., and Gillett, N. P.: Attribution of Extreme Events in Arctic Sea Ice Extent, J. Climate, 30, 553-571, https://doi.org/10.1175/JCLI-D-16-0412.1, 2017.

Kjeldsen, K. K., Korsgaard, N. J., Bjørk, A. A., Khan, S. A., Box, J. E., Funder, S., Larsen, N. K., Bamber, J. L., Colgan, W., van den Broeke, M., Siggaard-Andersen, M.-L., Nuth, C., Schomacker, A., Andresen, C. S., Willerslev, E., and Kjær, K. H.: Spatial and temporal distribution of mass loss from the Greenland Ice Sheet since AD 1900, Nature, 528, 396-400, https://doi.org/10.1038/nature16183, 2015.

Koenigk, T., Devasthale, A., and Karlsson, K.-G.: Summer Arctic sea ice albedo in CMIP5 models, Atmos. Chem. Phys., 14, 19871998, https://doi.org/10.5194/acp-14-1987-2014, 2014.

Kurtz, N. T. and Markus, T.: Satellite observations of Antarctic sea ice thickness and volume, J. Geophys. Res.-Ocean., 117, C08025, https://doi.org/10.1029/2012JC008141, 2012.

Kwok, R. and Cunningham, G. F.: ICESat over Arctic sea ice: Estimation of snow depth and ice thickness, J. Geophys. Res., 113, C08010, https://doi.org/10.1029/2008JC004753, 2008.

Li, J.-L. F., Lee, W.-L., Waliser, D. E., David Neelin, J., Stachnik, J. P., and Lee, T.: Cloud-precipitation-radiation-dynamics interaction in global climate models: A snow and radiation interaction sensitivity experiment, J. Geophys. Res.-Atmos., 119, 38093824, https://doi.org/10.1002/2013JD021038, 2014.

Li, J.-L. F., Richardson, M., Hong, Y., Lee, W.-L., Wang, Y.-H., Yu, J.-Y., Fetzer, E., Stephens, G., and Liu, Y.: Improved simulation of Antarctic sea ice due to the radiative effects of falling snow, Environ. Res. Lett., 12, 084010, https://doi.org/10.1088/17489326/aa7a17, 2017.

Massonnet, F., Fichefet, T., Goosse, H., Bitz, C. M., PhilipponBerthier, G., Holland, M. M., and Barriat, P.-Y.: Constraining projections of summer Arctic sea ice, The Cryosphere, 6, 13831394, https://doi.org/10.5194/tc-6-1383-2012, 2012.

Massonnet, F., Vancoppenolle, M., Goosse, H., Docquier, D., Fichefet, T., and Blanchard-Wrigglesworth, E.: Arctic sea-ice change tied to its mean state through thermodynamic processes, Nat. Clim. Chang., 8, 599-603, https://doi.org/10.1038/s41558018-0204-z, 2018.

Matthews, H. D., Gillett, N. P., Stott, P. A., and Zickfeld, K.: The proportionality of global warming to cumulative carbon emissions, Nature, 459, 829-832, https://doi.org/10.1038/nature08047, 2009.

Morrison, H. and Gettelman, A.: A New Two-Moment Bulk Stratiform Cloud Microphysics Scheme in the Community Atmosphere Model, Version 3 (CAM3). Part I: Description and Numerical Tests, J. Climate, 21, 3642-3659, https://doi.org/10.1175/2008JCLI2105.1, 2008.

Overeem, I., Anderson, R. S., Wobus, C. W., Clow, G. D., Urban, F. E., and Matell, N.: Sea ice loss enhances wave action at the Arctic coast, Geophys. Res. Lett., 38, L17503, https://doi.org/10.1029/2011GL048681, 2011.

Post, E., Steinman, B. A., and Mann, M. E.: Acceleration of phenological advance and warming with latitude over the past century, Sci. Rep., 8, 3927, https://doi.org/10.1038/s41598-018-22258-0, 2018.
Riahi, K., Rao, S., Krey, V., Cho, C., Chirkov, V., Fischer, G., Kindermann, G., Nakicenovic, N., and Rafaj, P.: RCP 8.5 - A scenario of comparatively high greenhouse gas emissions, Clim. Change, 109, 33-57, https://doi.org/10.1007/s10584-011-0149y, 2011 .

Rigor, I. G. and Wallace, J. M.: Variations in the age of Arctic seaice and summer sea-ice extent, Geophys. Res. Lett., 31, L09401, https://doi.org/10.1029/2004GL019492, 2004.

Rigor, I. G., Wallace, J. M., and Colony, R. L.: Response of Sea Ice to the Arctic Oscillation, J. Climate, 15, 2648-2663, https://doi.org/10.1175/15200442(2002)015<2648:ROSITT>2.0.CO;2, 2002.

Rolph, R. J., Mahoney, A. R., Walsh, J., and Loring, P. A.: Impacts of a lengthening open water season on Alaskan coastal communities: deriving locally relevant indices from large-scale datasets and community observations, The Cryosphere, 12, 1779-1790, https://doi.org/10.5194/tc-12-1779-2018, 2018.

Shiklomanov, N. I., Streletskiy, D. A., Swales, T. B., and Kokorev, V. A.: Climate Change and Stability of Urban Infrastructure in Russian Permafrost Regions: Prognostic Assessment based on GCM Climate Projections, Geogr. Rev., 107, 125-142, https://doi.org/10.1111/gere.12214, 2017.

Smedsrud, L. H., Halvorsen, M. H., Stroeve, J. C., Zhang, R., and Kloster, K.: Fram Strait sea ice export variability and September Arctic sea ice extent over the last 80 years, The Cryosphere, 11, 65-79, https://doi.org/10.5194/tc-11-65-2017, 2017.

Smith, L. C. and Stephenson, S. R.: New Trans-Arctic shipping routes navigable by midcentury, P. Natl. Acad. Sci. USA, 110 , E1191-E1195, https://doi.org/10.1073/pnas.1214212110, 2013.

Stanfield, R. E., Dong, X., Xi, B., Kennedy, A., Del Genio, A. D., Minnis, P., and Jiang, J. H.: Assessment of NASA GISS CMIP5 and Post-CMIP5 Simulated Clouds and TOA Radiation Budgets Using Satellite Observations. Part I: Cloud Fraction and Properties, J. Climate, 27, 4189-4208, https://doi.org/10.1175/JCLI-D13-00558.1, 2014.

Stroeve, J. C., Kattsov, V., Barrett, A., Serreze, M., Pavlova, T., Holland, M., and Meier, W. N.: Trends in Arctic sea ice extent from CMIP5, CMIP3 and observations, Geophys. Res. Lett., 39, L16502, https://doi.org/10.1029/2012GL052676, 2012.

Tan, I., Storelvmo, T., and Zelinka, M. D.: Observational constraints on mixed-phase clouds imply higher climate sensitivity, Science, 352, 224-227, https://doi.org/10.1126/science.aad5300, 2016.

Taylor, K. E., Stouffer, R. J., and Meehl, G. A.: An Overview of CMIP5 and the Experiment Design, B. Am. Meteorol. Soc., 93, 485-498, https://doi.org/10.1175/BAMS-D-11-00094.1, 2012.

Tietsche, S., Notz, D., Jungclaus, J. H., and Marotzke, J.: Recovery mechanisms of Arctic summer sea ice, Geophys. Res. Lett., 38, L02707, https://doi.org/10.1029/2010GL045698, 2011.

Zhang, J., Lindsay, R., Steele, M., and Schweiger, A.: What drove the dramatic retreat of arctic sea ice during summer 2007?, Geophys. Res. Lett., 35, L11505, https://doi.org/10.1029/2008GL034005, 2008. 